\title{
Optimization of The In-Process Control Process USING Six Sigma MeTHODS AND TOOLS
}

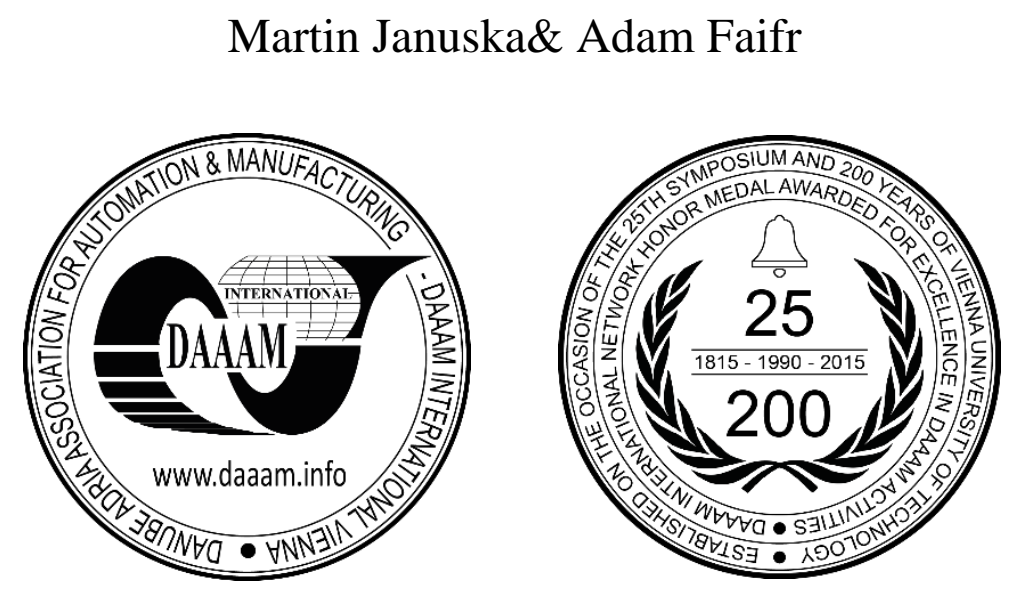

This Publication has to be referred as: Januska, M[artin] \& Faifr, A[dam] (2017). Optimization of the In-Process Control Process Using Six Sigma Methods and Tools, Proceedings of the 28th DAAAM International Symposium, pp.0280-0288, B. Katalinic (Ed.), Published by DAAAM International, ISBN 978-3-902734-11-2, ISSN 1726-9679, Vienna, Austria

DOI: $10.2507 / 28$ th.daaam.proceedings.038

\begin{abstract}
Presented paper deals with optimization of technological processes, particularly it is focused at quality control. Quality measuring is fundamental for any quality or process improvement. "If is not possible to measure it, it is not possible to manage it." In general it is possible to say that quality is measured at the process input, during the process (in-process control) and at the process output. This paper is focused at the in-process control and its quality itself. Paper presents the case study of optimization of the in-process control by using Six Sigma methods and tools in company producing medical technology and medical products in Czech Republic. Firstly, the description and analysis of in-process control is carried out, while the problem-causing factors are examined. Based on these findings, the proposals for process optimization follow. According to methodology, the DMAIC cycle is completed by the evaluation of process performance, where partial process performance indicators are designed.
\end{abstract}

Keywords: in-process quality control; quality; Six Sigma; process improvement; process quality; quality improvement

\section{Introduction}

Goal of this paper is to describe the process of in-process quality control, its limitations and possibilities for improvement. Six sigma methods and tools are successfully utilized in the presented case study from Czech company dealing with production of medical supplies. Quality processes are interesting due to completely different way of their assessment in compliance with production processes.

The performance of quality process is determined by the ability to correctly detect deviations of manufactured parts during their production. However, it is not the only starting point for process performance. For the quality process is to be efficient, the efficiency of the resources used is also important in addition to the quality of the work done, which is derived from the speed of the quality checks and controls. Therefore, eventual changes of the process can improve its performance in one aspect and worsen it in the other one. The purpose of this study is to examine how changes of all process aspects affect each other and consequently propose the possibilities of the process performance improvement. 


\section{Process management approach}

The process approach to organization management began to develop in the last two decades of the last century when it gradually began to replace the previous mainstream concept of corporate governance the functional approach. The main change over the functional approach is to look at the causes of the company's problems and the way they are solved where the processes are perceived purposefully in a relationship to the customer and not as standalone activities [12].

\subsection{Measuring process performance}

The systematic measurement of processes is an integral part of process control. Measuring process performance means activities designed to provide objective and accurate information about the progress of individual processes close to the real time so that processes can be continuously managed to meet all process requirements. There is huge difference between KPI (Key performance indicators) which are measured in real time or once a day or week and KRI (Key results indicators) measured once a month or year which are used for strategic planning.

From the business point of view measurement is necessary, among other things, in order to assess whether an enterprise fulfills defined objectives. In order to evaluate the performance of the process, it is also necessary to determine the base (etalon) with which the measured data will be confronted. Any changes to process outputs are conditioned by input changes and performance changes. If such changes in output or performance are not registered, no change can be expected. In order to control the change of output, the change of the inputs and the whole process of the process must also be controlled. Measurement of the process is a keystone of the process management. In other words if it is not possible to measure it, it is not possible to manage it [11].

\subsection{Process improvement}

In general, it can be argued that the need to improve processes arises at the moment when a certain shortcoming is discovered. From the point of view of keeping firms on the market, that is the time when is necessary to improve processes. The key factor in the need for change is the customer and his market position, which has changed significantly over the past two decades. Customers are demanding products and services higher and higher quality. Every business which wishes to stay on the market for a long time has to think the same way.

However, in order for processes to be improved, it is first necessary to identify their shortcomings. There are two basic approaches to improvement - continuous and discontinuous. Continuous approach is based on continuous improvement of processes based on continuous monitoring of process characteristics, ie process measurement.

The Six Sigma philosophy[2][8][9][14] used in process optimization is the DMAIC cycle consisting of five basic steps:

- Definition of process and problem

- Measurement of process variables (input, output, sources)

- Analysis of process deficiencies, finding causes of the problem

- Identifying opportunities and improving process performance

- Controlling proposed measures based on defined indicators

\section{In-process control}

For the presented case study the process of inter-operative control at Gerresheimer Horšovský Týn spol. s.r.o., a company operating in the Czech Republic, which is part of the global group of companies Gerresheimer. The Gerresheimer Group is a major producer of a wide range of medical technology and medical products.

The process of inter-operational control is part of corporate quality control, along with input and output control. Quality controls take place during ongoing production, where the checkpoint is always located behind each production step for better detection of nonconforming product but also to better determine the location and cause of the problem.

From the point of view of individual steps, the process can be divided into five basic phases, namely:

- Planning the test

- Selecting the sample

- Testing the sample

- Enter the result into the system

- Dismantling or archiving of the samples tested

The underlying issue of this case study is the reduced flexibility of the process leading to an increase in the cost of securing the process due to the increase in overtime. The following analysis is therefore carried out with regard to the problem examined in order to identify the options for solving the problem. 


\subsection{Input-Requirements for control}

The product control plan is the main input for the control. The product control plan determines which tests and at what intervals will be performed at the product during the production cycle. This document is created separately for each component and determines the method of sampling, the type of tests to be performed, the interval of their execution and the location and equipment used for the testing.

On the basis of the control plan and data from current production, test requirements are generated. In the monitored period from April to June 2016, a total of 41,328 tests were performed in the department, which means a requirement to run the test every 3 minutes in 24/7 operation system.

The process is eligible if the measured values move between the acceptability limits and all fluctuations are caused by random causes. In this case, the temporary interruption of production on a smaller number of production facilities would be considered as such a random cause. If the process has only these random effects, the process is considered statistically mastered in the Six Sigma control system. The limit of the effects of these random causes is the deviation of values from the mean of the selection (UCL, LCL). The limit is usually determined as three times the standard deviation from the mean in both possible directions. In case of higher stability, the set tolerances may be lower [7] [9] [13].

The chart below shows a graph of the number of tests converted to a workplace in the two laboratories under study referred to as 4.7.I and 4.7.II. The graph shows marked variability in both directions from the CL border, especially in tests performed in the second control laboratory. Whilst during the month of April the number of tests performed exceeds the accepted upper limit (UCL), then in the second half of April this value decreases significantly so that in the following months the number of tests per worker is reduced to the lower acceptable limit (LCL).

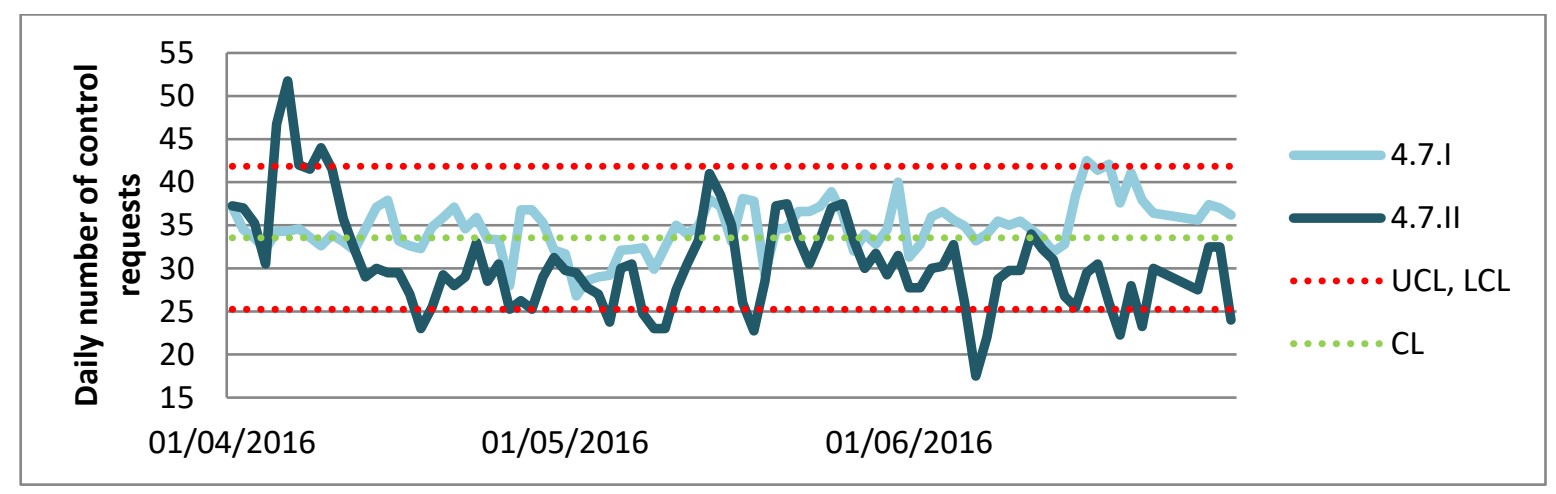

Fig. 1. Input variability progression

\subsection{Output - Control results entering}

The output of the process is that the results of the control are entered into the MES system. The number entered records should correspond to the number of requirements for control. Average necessary time since the requirement for a new test until entering the result into MES in the reference period lasted 49 minutes.

The following figure shows a graph describing the development of the daily average test time over the reference period. Trends were used to describe the trend over the last three days. It can be seen from the graph that, including fluctuations in average time, the test period are gradually extending.

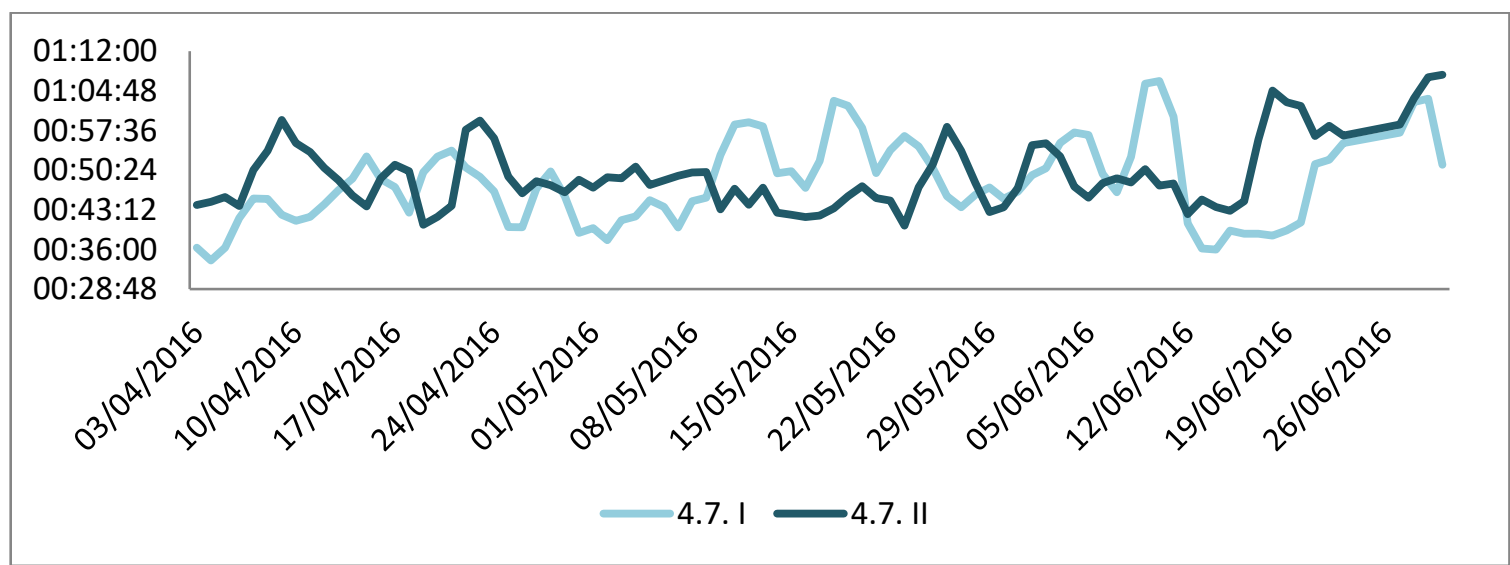

Fig. 2. Daily averages of inspection time 


\subsection{Material flow}

The spaghetti diagram serves as a basis for visualizing the current flow of the process. This is a snapshot showing the current flow of material, information, or people in the process [3].

Control rooms are divided into two control laboratories. Non-control workers are also commonly employed in laboratories. The goal of material flow mapping is to place the process-related regulation into a real spatial framework. The current flow of material in IPC laboratories is described in the following figure. As shown in the blue interrupted rectangles, the spaces for the individual types of checks are indicated. The orange flow is then indicated by the material flow of the selected control type - combined visual and dimensional control.

The numbering of the control steps is assigned as follows:

1. Receiving the material for exam

2. 1st Control Point - Visual Exam

3. Preparations for the dimensional test

4. 2nd Inspection site - Dimensional test

5. Preparations for dimensional

6. Temporary storage - in the laboratory 4.7 I Transient sample retention has been observed after all tests have been performed. This storage is inconsistent with the process manuals.

7. Discard or archive samples
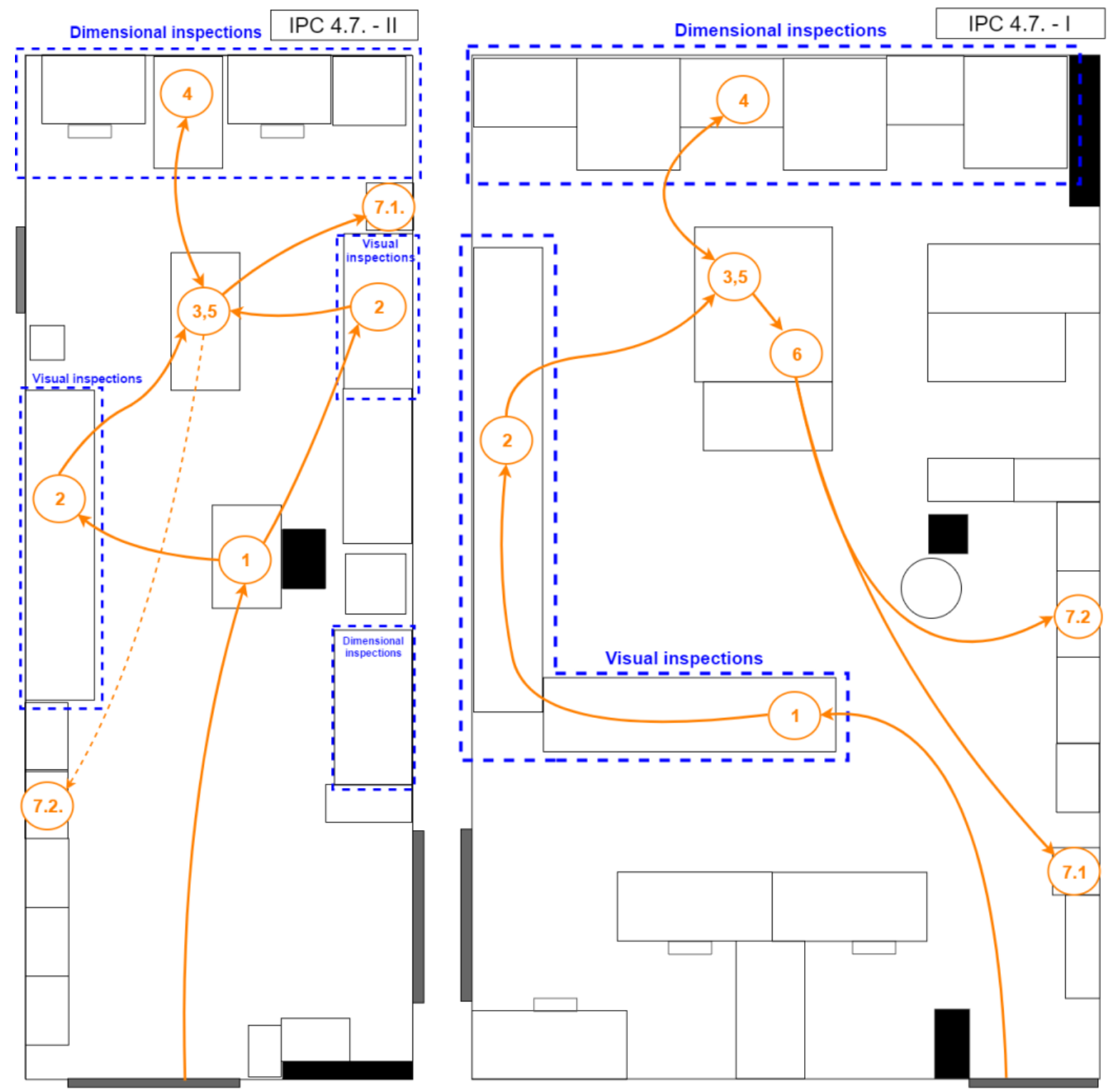

Fig. 3. Previous layout of control laboratories 


\section{Process analysis}

Based on the description of the process characteristics, key process variables were described. From the above, the following factors are most important:

- Fluctuations in the number of tests per worker

- Different levels of laboratory testing

- The fluctuating average test duration

- Prolonged average test time

- There may be violations of process and work instructions

- Areas are shared with non-quality control staff

The aim of optimizing the process is therefore the elimination of individual risk factors as much as possible. The primary prerequisite for the process is that if the testing takes an average of longer time, then one worker performs fewer tests on average and increases the need to increase the number of workers on the shift, thereby increasing the cost of running the process accordingly.

Based on this assumption, an analysis of the dependence between input level and average test time will be performed. The dependency pattern is shown in the following figure where the trend is visible, but the low reliability of the measured data does not allow this hypothesis to be rejected.

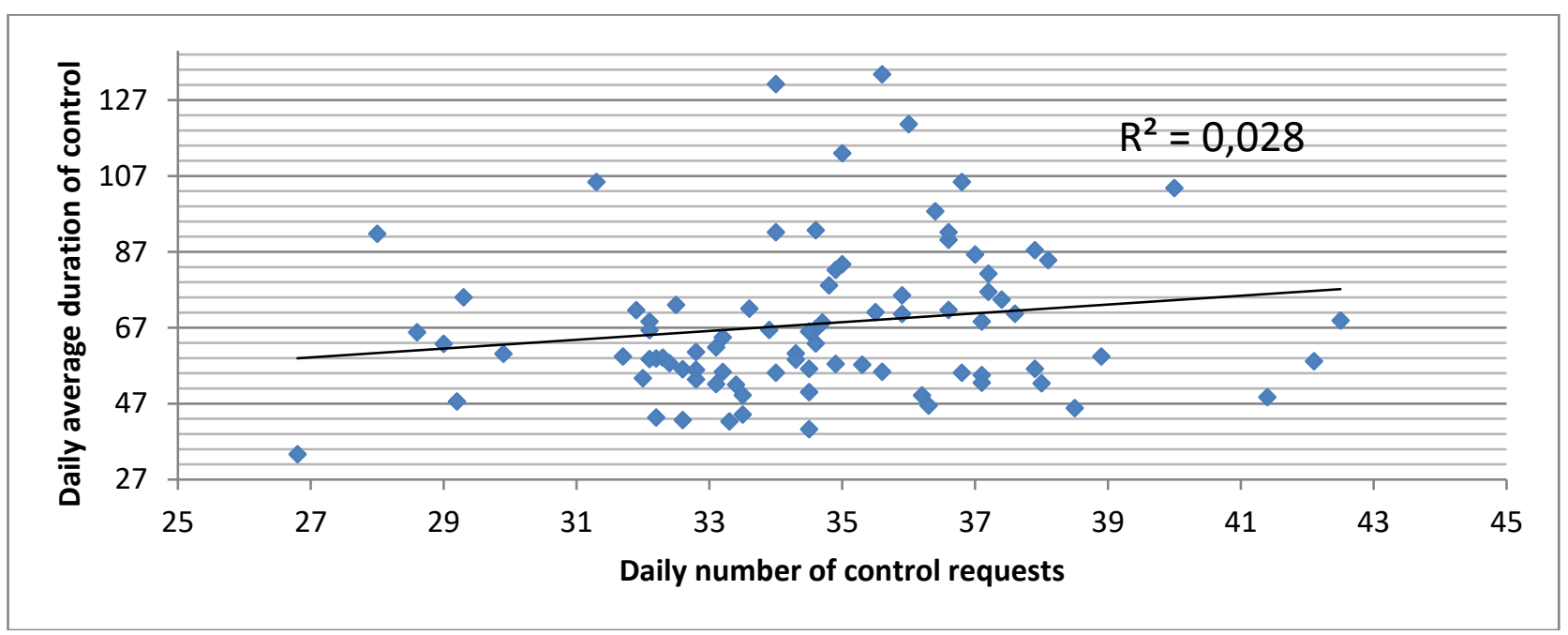

Fig. 4. Output regression analysis

In order to identify other possible causes of the prolongation of the test period, an Ishikawa diagram is compiled. The diagram defines, in an ordered form, the cause of the consequence. The diagram allows to find the real causes of the problem, not just the symptoms of the consequence [5].

The various potential causes can be divided according to defined areas:

Management

- Organization of control activities - refers to the division of the individual shifts and the assignment of tasks beyond the normal control activity

Workers

- Qualification of workers - Higher qualifications should also lead to higher speeds of testing

- Occupation of shift - temporary incomplete shift occupation (leave, incapacity for work, etc.)

Procedure

- Non-optimal follow-up of control steps - the control procedure is defined in cooperation with the customer (see the control plan)

Process

- Entry variability - workers may be overloaded with tests

Devices

- Device malfunctions - occupy $3.44 \%$ of control activity

- Insufficient equipment - may complain about the control activity, however the influence on the extension of the test processing time is minimal 


\section{Environment}

- Spatial layout of laboratories - results from the current material flow in IPC laboratories. Some measuring devices are located outside of the lab, which can significantly increase transport time while complaining about handling control samples. There may also be a lack of clarity when handling samples.

- Disturbing elements - laboratories are shared with other workers, increased movement in laboratories may reduce the ability of workers to concentrate.

\section{Process improvement proposals}

The proposed measures should lead to increased process efficiency. Therefore, it is not possible to choose proposals that will achieve the desired effect (reducing the running time of the tests and reducing personnel costs) to the detriment of quality.

From the analyzed possible causes of the problem in the process, the proposal for a new organization of control laboratories and a change in the way control activities were organized were identified as potential opportunities for performance improvement. Another measure should aim to reduce the failures of used equipment.

\subsection{Layout of control laboratories}

In the cause and effect analysis, one of the possible potential causes of the extension of the test time was the current environment where the control is taking place. Specifically, this was a possible spatial arrangement that could prolong the transport time of the samples and thus extend the testing time as such. The second possible cause was the possible disturbance of control staff by non-control staff, which may, in addition to prolonging the testing, lead to a decrease in the number of workers and thus a decrease in the quality of the work performed.

The improvement proposal envisages a new spatial arrangement of control laboratories. The new plan envisages the centralization of control into a single room, where all control devices and places for workers will be moved from the IPC 4.7 II. laboratory to IPC 4.7 I. At the same time, all non-controllrealted devices will be moved to the IPC 4.7 II.laboratory.

This change should reduce the average transport distance of the controlled samples by $14.6 \%$. Only direct manipulation of samples within the laboratories should save $36.78 \mathrm{~km}$ per month. Further improvements are expected from the viewpoint of the control environment where the movement of non-statutory personnel in laboratories should be significantly reduced, which should only enter the laboratory again with the benefit of parts for inspection and for the removal of empty containers back into production.

A new sampling site is set where the production staff will place the parts to be tested. Further, the objects for sample destruction are moved to the penultimate process step. This will, among other things, reduce the risk of mixing in the space for dimensional test preparations.

\subsection{Increase of flexibility of the control team}

Changing the organization of control laboratories and centralizing the process into one room will remove the physical barrier in the context of testing. Moving into one control laboratory can increase the substitutability of workers in the event of outages.

The limiting factor of change is the knowledge of inter-operative control workers in the field of checks on the remaining products. The knowledge of an inter-operative control worker can be structured into four layers in descending order as follows:

- Knowledge of the quality management system in the company

- Knowledge of capturing information

- Knowledge of the inter-operative control process

- Knowledge of the product, including how to perform specific controls

The first three levels of knowledge are common to all inter-operative control staff. Reorganization of the control system therefore requires the updating of the knowledge of the last level.

The first step of the reorganization is the implementation of staff training leading to the dissemination of knowledge in other processes. However, the training itself does not achieve the desired status. In order for a worker to carry out his / her own work in accordance with the knowledge gained, it is necessary to convert this explicit knowledge into tactile knowledge. This can only be achieved through practical activities, in this case by carrying out specific tests. The duration of this transfer depends on the entry level of the worker's knowledge and also the ability to acquire knowledge [1] [10].

The benefit of this measure is easier way to replace the individual IPC control staff in the event of a staff shortage, which should bring the desired effect of reducing the overtime hours by $69 \%$. In total, this is a saving of 5,424 overtime hours. Another effect is a more even distribution of controls among individual workers, where the controls will not be allocated based on assignment to a specific project.

From the point of view of the development of the input, the variability of the variability (number of test requirements) will be significantly reduced, where the original fluctuations between the laboratories will be mutually attenuated. 


\section{Measuring process performance}

There is no benchmark for any process that would ideally affect all aspects of the performance of each process. Therefore, the introduction of a new indicator is not a creation of a universal indicator, but one that best describes the activity under consideration and which is best suited to the needs of the user. Therefore, when introducing a new performance benchmark, it is important to ask: "How can this measure improve the performance of the activity?"

\section{Cost of non-quality (IPC)}

Measurement of costs due to inferiority can, in a reversed form, express the quality of the company's management or subprocess. Although this indicator is commonly used in the enterprise, it is not further analyzed. This provides information on the quality management system as a whole. The purpose of introducing this indicator is to allocate the costs incurred according to the place of inferiority. Its aim is therefore to measure only the costs that have arisen in a particular process. In this case, the process of inter-operative control.

The indicator calculation is defined by the following equation:

$$
C N Q_{I P C}=\frac{\text { costs due to inferiority(in time period) }}{\text { unit turnover (in time period) }} * 100
$$

In relation to the CNQ business indicator, this indicator is given by the sum of the cost of the iferior partial processes to the unit's turnover.

\section{Documentation Right First Time}

The error caused by bad writing will normally lead to waste. This metric concerns misspellings in documents processed in the process. This is a list of internal complaints or mistakes when entering test results.

The pointer is defined by the following equation:

$$
D R F T_{I P C}=\left(1-\frac{\text { The number of documentation error reports }}{\text { total number of reports }}\right) * 100
$$

\section{Controls processed in time}

The purpose of introducing this indicator is to measure whether the process is capable of meeting its demands in terms of the speed of the tests being carried out. Two variables are defined for the calculation.

The calculation is given by the following equation:

$$
C I T_{I P C}=\frac{\text { numer of tests performed in time }}{\text { total number of tests }} * 100
$$

\section{Activity processed Index}

In addition to control activities, IPC control officers are entrusted by their superiors with ad hoc control activities beyond the control plan. For example, it is a product review or additional measurement if the actual cause of the problem can be detected or in case of investigation of the influence of the newly used material etc. This indicator is inversely proportional to the CIT and QCI . The higher the amount of time consumed for conducting routine checks, the less time can be used for further testing.

The calculation is given by the following formula:

$$
\boldsymbol{A P I _ { I P C }}=\frac{\text { Number of finished activities in given time period }}{\text { Number of required activities in given period }} * 100
$$

\section{Quality controls Index}

Measurement of the level and variability of the input of the process provides information on the quantitative mode in which control is taking place. Although this indicator does not measure the ability to meet process requirements, it can analyze outputs based on these data.

A high entry rate can negatively affect either the quality of the tests performed or the speed of the tests being carried out. The calculation is defined by the following equation:

$$
Q C I_{I P C}=\frac{\text { total } \text { number of required tests }}{\text { monthly average of required tests }}
$$




\section{Evaluation of process performance}

The previous section describes the possibilities of introducing sub-performance indicators in relation to the aspects of the inter-operational control process. As has been said above, improving one of the performance aspects can also mean a reduction in performance by the optics of the second aspect.

The aim of introducing a synthetic scale is to summarize all aspects of the process under review. In order to be able to evaluate the various aspects in a comprehensive way, it is necessary to build individual sub-indicators against each other and evaluate their impact on the overall performance of the process.

The so-called spider diagram (also referred to as the radar diagram) can be used to monitor process performance in individual aspects. The Radar Diagram is one of the tools used by Six Sigma philosophy. The graph shows the velocity data on its own axes in a spin-off manner. This method of recording results is appropriate when it is necessary to clearly evaluate several characteristics in one place. The characteristics are always based on the standard [4].

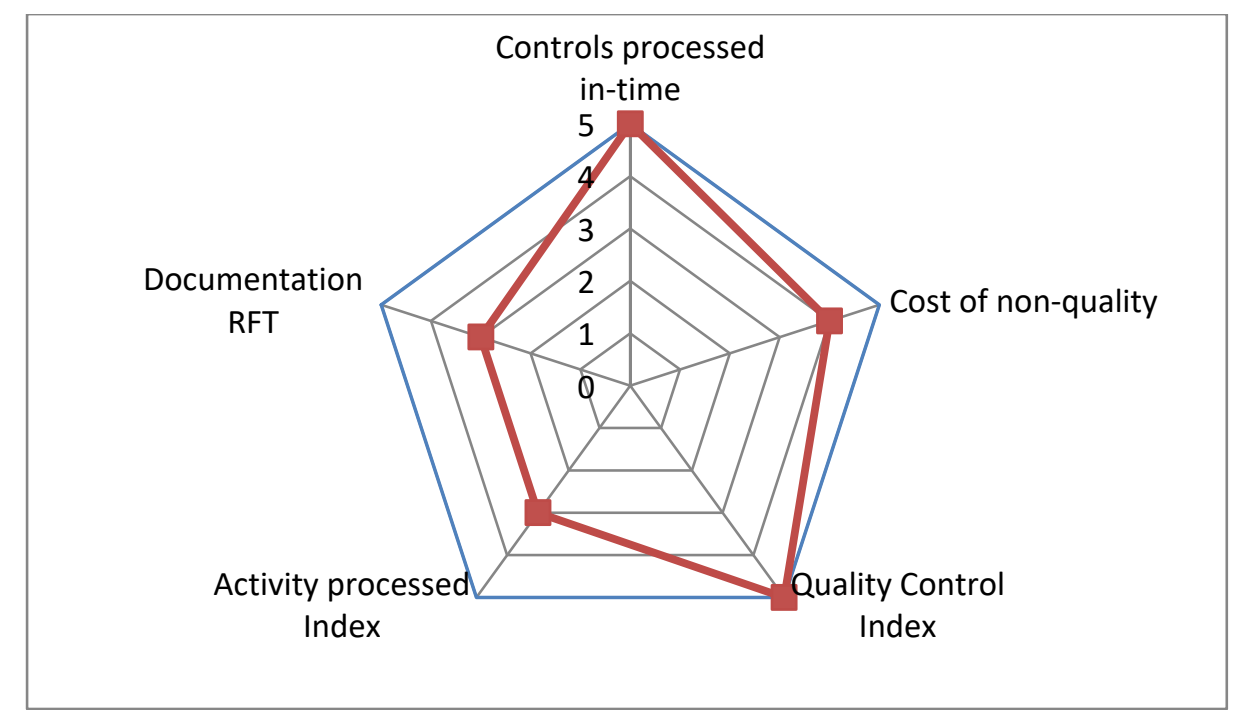

Fig. 5. Process performance diagram

The standard should be set to match the values of the characteristics. Values can be converted to spot scores. For example, 5 points means the best possible result, 3 points mean the average score, 0 means absolutely the worst possible result.

Besides the process performance determination, the proposed indicators can be further exploited in several other areas. The basic design calculates the aggregate indicators for the whole control process together. However, the method of processing the results can be tailored to the needs of the process management, both by time and by organizational units.

Unit rating permits a better chance of responding adequately to eventual performance reductions by locating the right site of potential shortage. All the information thus obtained can serve as a basis for better planning in all aspects of the process.

\section{Conclusion}

The aim of this paper was to investigate the process of interoperative control, its pitfalls and the possibilities of its improvement. In addition to the role of quality assurance in the enterprise, the choice of this process is a different way of evaluating its performance than that of value-creation (production) processes. The performance of this process is determined by the ability to correctly detect deviations of manufactured parts during their production. However, this is not the only starting condition for process performance. If the process is to be effective, it is also important for the quality of the work to be done, as well as the efficiency of the resources used, which is derived from the speed of the quality controls.

It is precisely the efficiency of resource utilization in the process and the possibility of increasing economic efficiency as the main objective of the investigation, while respecting all process constraints and process performance factors. The underlying issue of this case study was the reduced flexibility of the process leading to an increase in the cost of securing the process due to the increase in overtime. DMAIC Cycle, as a Six Sigma Continuous Improvement Project, was used to analyse this issue. In addition, tools that are commonly used in this process have been used.

Firstly, the process was defined and an analysis of the process was carried out, where important factors influencing the output were first identified, followed by the analysis of their causes with respect to the problem solved. Subsequent measures proposed could not offer a solution that would increase one of the monitored indicators at the expense of the other. To increase the flexibility of the process does not mean reducing the speed or quality of the controls performed. 
Based on these findings, the optimization of the laboratory layout was proposed, as well as the reorganization of the control team. Due to these proposals the expected overtime costs reduced by approximately $69 \%$, where all related expenditure should be covered by increased process effectiveness within 130 days.

Moreover, continuous improvement is further driven by continuous measurement and monitoring of process developments. Therefore, partial performance indicators were designed to monitor both the development of inputs and, in particular, the development of output - the average duration of the controls and its quality.

As this work has shown, Six Sigma tools and methods can also be used for controlling processes.

\section{References}

[1] Dalkir, K. (2011). Knowledge management in theory and practice. 2nd ed.Mass.: MIT Press, ISBN 978-0-262-015080. Cambridge

[2] Furterer, S. (2009). Lean Six Sigma in Service: Applications and Case Studies, CRC Press, 9781420079104, Boca Raton

[3] George, N. (2010). Kapesnípříručka Lean Six Sigma: rychlý průvodce téměř 100 nástroji na zlepšování kvality procesů, rychlosti a complexity, SC\&C Partner, 978-80-904099-2-7, Brno

[4] Gil, J., Howse, J., \& Kent, S. (1999). Formalizing spider diagrams. In Visual Languages, 1999. Proceedings. 1999 IEEE Symposium on (pp. 130-137). IEEE.

[5] Ishikawa, K. (1985). What is total quality control? The Japanese way. Prentice Hall.

[6] Kolosowski, M.; Duda, J. \& Tomasiak, J. (2016). Statistical process control in conditions of piece and small lot production, Proceedings of the 26th DAAAM International Symposium, pp.0147-0155, B. Katalinic (Ed.), Published by DAAAM International, ISBN 978-3-902734-07-5, ISSN 1726-9679, Vienna, Austria

[7] Kralikova, R., Rusko, M. \& Wessely, E. (2012). Framework for Applying Six Sigma Methods within Environmental Management, Chapter 45 in DAAAM International Scientific Book 2012, pp. 545-552, B. Katalinic (Ed.), Published by DAAAM International, ISBN 978-3-901509-86-5, ISSN 1726-9687, Vienna, Austria

[8] Mahato, S.; Dixit, A. \& Agrawal, R. (2017). Application of Lean Six Sigma for cost-optimised solution of a field quality problem: A case study. PROCEEDINGS OF THE INSTITUTION OF MECHANICAL ENGINEERS PART B-JOURNAL OF ENGINEERING MANUFACTURE, Vol. 231, (MAR 2017) page numbers (713-729), ISSN09544054

[9] Michalek, J. (2006). Statisticka regulace procesu (SPC), Ceska spolecnost pro jakost, 80-02-01810-9, Prague

[10] Mladkova, L. (2004). Management znalostí v praxi. Professional Publishing, 80-86419-51-7. Praha

[11] Nenadal, J. (2004). Mereni v systemech management jakosti, Management Press, 80-7261-110-0, Prague

[12] Repa, V. (2012). Procesne rizena organizace, Grada, 978-80-247-4128-4, Prague

[13] Tent, I.-D., Dumitrescu, C.-D. \& Trandafir, N. (2010). Statistical quality control methods of products and services. In Proceedings of the 21st DAAAM International Symposium. Viena : DAAAM International, 2010. ISBN 978-3901509-73-5.

[14] Wessel, G., \& Burcher, P. (2004). Six Sigma for small and medium-sized enterprises. The TQM Magazine, 16(4), 264-272.7 